\title{
The effect of exenatide on fasting bile acids in newly diagnosed type 2 diabetes mellitus patients, a pilot study
}

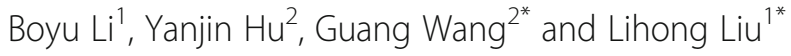

\begin{abstract}
Background: Glucagon-like peptide-1 receptor agonists (GLP-1 RAs) demonstrated good glycemic efficacy in patients with type 2 diabetes mellitus (T2DM) recent years, whereas studies on GLP-1 RAs' biliary effects were limited. Therefore, we aimed to assess the effect of exenatide on bile acids (BAs) and investigate the role of BAs in the glycemic control effect of exenatide.
\end{abstract}

Methods: Thirty-eight newly diagnosed T2DM participants without glucose-lowering drugs intake were recruited. Plasma total bile acids in fasting state (FTBAs) and other parameters were tested at baseline. Then exenatide were applied to the T2DM participants for 12 weeks. FTBAs and glycemic parameters were measured again after exenatide treatment, and correlation analysis between changes of FTBAs and glycemic parameters were conducted to investigate the role of BAs in the glycemic control effect of exenatide.

Results: The baseline FTBAs level of T2DM patients had no significance (3.84 \pm 2.06 vs. $3.87 \pm 2.89, P=0.954)$ compared with healthy subjects. After 12-week exenatide treatment for the T2DM patients, FTBAs were decreased from $3.84 \pm 2.06 \mu \mathrm{mol} / \mathrm{L}$ to $3.06 \pm 1.27 \mu \mathrm{mol} / \mathrm{L}(P<0.01)$. The correlation analysis showed that changes of FTBAs was positively correlated with changes of FPG $(r=0.355, P<0.05)$.

Conclusions: Our results demonstrated a decreased FTBAs level after exenatide treatment for 12 weeks, without the interference of metformin and other glucose-lowering drugs. The reduction of FTBAs might not exert a positive role in the glycemic control effect of exenatide.

Trial registration: Trial registration number: NCT04303819. Registered in March 11, 2020 - Retrospectively registered.

Keywords: Exenatide, Type 2 diabetes mellitus, Bile acids, Glycemic control

\section{Background}

Glucagon-like peptide-1 receptor agonists (GLP-1 RAs) demonstrated good glycemic efficacy in type 2 diabetes mellitus (T2DM) patients recent years [1]. This class of drugs exploited the insulinotropic and glucagonostatic effects of GLP-1, thereby effectively lowering blood glucose

\footnotetext{
*Correspondence: drwg6688@aliyun.com; liulihong@bjcyh.com

${ }^{2}$ Department of Endocrinology, Beijing Chao-Yang Hospital, Capital Medical University, 8 Gongtinan Road, Chaoyang District, Beijing 100020, China 'Department of Pharmacy, Beijing Chao-Yang Hospital, Capital Medical University, 8 Gongtinan Road, Chaoyang District, Beijing 100020, China
}

[2]. In addition, GLP-1 (receptor agonists) inhibits gastric emptying, gastric acid secretion and other aspects of proximal gastrointestinal physiology, for example its role in biliary physiology [2].

Bile acids (BAs) are synthesized in liver from cholesterol and released in the intestinal lumen upon food intake [3]. The physiology of BAs was traditionally considered related to its contribution to the assimilation of fat and fat-soluble vitamins $[4,5]$. Recent research suggested that BAs also functioned as a metabolic integrator in regulation of glucose metabolism [6-10] and

C C The Author(s). 2020 Open Access This article is licensed under a Creative Commons Attribution 4.0 International License, which permits use, sharing, adaptation, distribution and reproduction in any medium or format, as long as you give appropriate credit to the original author(s) and the source, provide a link to the Creative Commons licence, and indicate if changes were made. The images or other third party material in this article are included in the article's Creative Commons licence, unless indicated otherwise in a credit line to the material. If material is not included in the article's Creative Commons licence and your intended use is not permitted by statutory regulation or exceeds the permitted use, you will need to obtain permission directly from the copyright holder. To view a copy of this licence, visit http://creativecommons.org/licenses/by/4.0/. The Creative Commons Public Domain Dedication waiver (http://creativecommons.org/publicdomain/zero/1.0/) applies to the data made available in this article, unless otherwise stated in a credit line to the data. 
appetite [11], through binding to the nuclear hormone farnesoid X receptor (FXR) and Takeda G protein receptor 5 (TGR5) in multiple organs, leading to regulation of intestinal incretin secretion, hepatic gluconeogenesis, glycogen synthesis and energy expenditure [12]. Thus, BAs must have a role in the glycemic control effect of GLP-1 RAs.

Studies on GLP-1 RAs' biliary effects were limited and sometimes controversial. Acute administration of exenatide markedly reduced cholecystokinin stimulated gallbladder emptying by $40 \%$ in healthy volunteers [13]. Whereas, there was another study demonstrated that liraglutide increased serum levels of deoxycholic acid in the fasting state and postprandial state in T2DM patients [14]. Therefore, we aimed to access the effect of exenatide on BAs and investigate the role of BAs in the glycemic control effect of exenatide.

\section{Methods}

\section{Participants}

Thirty-eight newly diagnosed T2DM patients and 38 healthy subjects with matched BMI were recruited from the endocrinology department of the Beijing Chao-Yang Hospital between January 2014 and January 2015, following the methods of G. Wang et al. 2016 [15]. The diagnostic criteria of T2DM were in accordance with the World Health Organization criteria of 1999 [16]. T2DM patients were excluded if they had a history of hepatobiliary or pancreatic diseases, a history of glucose-lowering drugs intake, change of anti-dyslipidemia therapy regimen, an estimated glomerular filtration rate $<60 \mathrm{~mL} / \mathrm{min} / 1.73 \mathrm{~m}^{2}$, pregnancy or alcohol intake $>3$ units/d. All subjects gave their written, informed consent to participate.

\section{Intervention}

Thirty-eight newly diagnosed T2DM patients received 12 weeks of exenatide injection, $5 \mu \mathrm{g}$ twice daily by subcutaneous injection for 4 weeks, followed by $10 \mu \mathrm{g}$ twice daily for 8 weeks, as recommended by the drug manufacturer. Other than that, they didn't take any other glucose-lowering drugs.

\section{Laboratory measurements}

Total cholesterol (TC), low-density lipoprotein cholesterol (LDL-C), high-density lipoprotein cholesterol (HDL-C), triglycerides (TG), fasting plasma glucose (FPG) and FTBAs were tested using Dimension RxL auto analyzer (Dade Behring Diagnostics, Deer-field, IL, USA). Glycated hemoglobin A1c (HbA1c) was estimated by highperformance liquid chromatography using HLC-723G7 analyzer (Tosoh Corporation, Tokyo, Japan). Fasting serum insulin (FINS) and C-peptide were measured by Access 2 immunoassay system (Beckman Coulter, Inc., Brea, CA, USA). FTBAs was measured by Total Bile Acids Kit (Enzymatic Cycling assay) (Biosino Bio-Technology and science Inc., Beijing, China). Homoeostasis model assessment for insulin resistance $($ HOMA-IR) $=$ FPG $(\mathrm{mmol} / \mathrm{L}) \times \mathrm{FINS}(\mathrm{mU} / \mathrm{L}) / 22.5$, and homeostasis model assessment $\beta$ (HOMA-B) was used to estimate $\beta$-cell function and calculated by HOMA-B $=20 \times$ FINS $(\mathrm{mU} / \mathrm{L}) /$ [FPG $(\mathrm{mmol} / \mathrm{L})-3.5]$ [17]. Changes in parameters were expressed as delta parameters, $\Delta=$ parameter (after exenatide treatment) - parameter (pre-treatment).

\section{Statistical analysis}

Variables which were normally distributed, such as age, BMI, TC, LDL-C, HDL-C, glucose, FINS, C-peptide, HbA1c and FTBAs, were analyzed by Student's t test and expressed as means $\pm \mathrm{SD}$. Variables which were not normally distributed, such as TG, HOMA-IR and HOMA-B, were analyzed by the Mann-Whitney $\mathrm{U}$ test or Wilcoxon test, and expressed as medians (interquartile range, IQR). Correlations between changes of FTBAs and glycemic parameters were measured using the Pearson correlation technique. All analyses were performed using SPSS 22.0 (IBM SPSS Inc., Chicago, IL, USA), and a two-side $P$-value $<0.05$ was considered statistically significant.

\section{Results}

Baseline characteristics

Baseline characteristics were presented in Table 1. T2DM patients and the healthy subjects had no significance in age and BMI. There was difference in LDL, TG and FPG due to the diabetic pathological status. We measured FTBAs and found no difference (T2DM patients vs. healthy subjects, $3.84 \pm 2.06$ vs. $3.87 \pm 2.89, P=0.954$ ).

Table 1 Baseline characteristics

\begin{tabular}{llll}
\hline Parameters & $\begin{array}{l}\text { T2DM patients } \\
(n=38)\end{array}$ & $\begin{array}{l}\text { Healthy subjects } \\
(n=38)\end{array}$ & $\begin{array}{l}P \text { - } \\
\text { value }^{a}\end{array}$ \\
\hline Age, years & $48.2 \pm 9.0$ & $52.9 \pm 15.7$ & 0.074 \\
Male, $\%$ & $17,44.7 \%$ & $18,47.4 \%$ & \\
Height, $\mathrm{cm}$ & $170.7 \pm 9.4$ & $171.7 \pm 6.02$ & 0.572 \\
Weight, $\mathrm{kg}$ & $93.1 \pm 17.1$ & $90.1 \pm 8.3$ & 0.722 \\
BMl, $\mathrm{kg} / \mathrm{m}^{2}$ & $31.2(28.5,35.1)$ & $30.8(27.7,33.9)$ & 0.684 \\
TC, $\mathrm{mmol} / \mathrm{L}$ & $5.05 \pm 1.11$ & $4.09 \pm 0.77$ & $<0.01$ \\
HDL-C, mmol/L & $1.15 \pm 0.46$ & $1.14 \pm 0.30$ & 0.995 \\
LDL-C, mmol/L & $2.92 \pm 0.80$ & $2.23 \pm 0.54$ & $<0.01$ \\
TG, mmol/L & $2.16(1.26,4.21)$ & $1.30(0.87,2.07)$ & $<0.01$ \\
FPG, $\mathrm{mmol} / \mathrm{L}$ & $9.19 \pm 3.46$ & $4.41 \pm 0.95$ & $<0.01$ \\
FTBAs, $\mu \mathrm{mol} / \mathrm{L}$ & $3.84 \pm 2.06$ & $3.87 \pm 2.89$ & 0.954 \\
\hline
\end{tabular}

Data presented as means \pm SD or medians (interquartile range)

$P$ value was calculated by independent sample $T$ test

${ }^{\mathrm{a}} \mathrm{T} 2 \mathrm{DM}$ patients vs. healthy subjects 


\section{Changes of FTBAs and glycemic parameters after 12-week exenatide treatment}

The T2DM patients were given an injection of exenatide for 12 weeks, then changes of FTBAs and other metabolic parameters were measured (Table 2). Weight, BMI, TC and TG levels were significantly decreased after 12-week exenatide treatment compared with pre-treatment. FTBAs were decreased from $3.84 \pm 2.06 \mu \mathrm{mol} / \mathrm{L}$ to $3.06 \pm$ $1.27 \mu \mathrm{mol} / \mathrm{L}(P<0.01)$ (Fig. 1a). FPG was decreased from $9.19 \pm 3.46 \mathrm{mmol} / \mathrm{L}$ to $6.42 \pm 1.08 \mathrm{mmol} / \mathrm{L}(P<0.01)$ (Fig. 1b). HOMA-IR was decreased from $3.02(2.18-5.16)$ to 2.80(1.95-4.42), with no statistical significance (Fig. 1c). HOMA-B was increased from 38.81(20.13-61.98) to 79.60(48.47-106.09) $(P<0.01)$ (Fig. 1d).

\section{Correlations between changes of FTBAs and glycemic parameters}

We conducted a correlation analysis to access the correlation between changes of FTBAs and glycemic parameters. We found that $\triangle$ FTBAs was positively correlated with $\triangle$ FPG $(r=0.355, P<0.05)$ (Fig. 2a). We did not see statistical significance in correlation between $\triangle$ FTBAs and $\triangle$ HOMA-B $(r=-0.312, P=0.057)$ (Fig. 2b).

\section{Discussion}

To avoid the interference of metformin and other glucose-lowering drugs on BAs, newly diagnosed T2DM participants without glucose-lowering drugs intake history were recruited. As well known, several drugs may affect the enterohepatic circulation of BAs, namely metformin, inhibitors of the apical sodium-dependent bile acid transporter (ASBT) $[18,19]$ and bile acids sequestrants (BASs) [20, 21]. Metformin had an effect on BAs reabsorption on intestinal L cells [22]. It may decrease

Table 2 Change of parameters after 12-week exenatide treatment in T2DM patients $(n=38)$

\begin{tabular}{llll}
\hline Parameters & Pre-treatment & Exe-treatment & $P$-value \\
\hline Weight, $\mathrm{kg}$ & $93.1 \pm 17.1$ & $86.2 \pm 18.1$ & $<0.01$ \\
$\mathrm{BMI}, \mathrm{kg} / \mathrm{m}^{2}$ & $31.2(28.5-35.1)$ & $29.4(25.3-32.8)$ & $<0.01$ \\
$\mathrm{TC}, \mathrm{mmol} / \mathrm{L}$ & $5.05 \pm 1.11$ & $4.30 \pm 0.92$ & $<0.01$ \\
$\mathrm{HDL}-\mathrm{C}, \mathrm{mmol} / \mathrm{L}$ & $1.15 \pm 0.46$ & $1.14 \pm 0.28$ & 0.899 \\
$\mathrm{LDL}-\mathrm{C}, \mathrm{mmol} / \mathrm{L}$ & $2.92 \pm 0.80$ & $2.57 \pm 0.83$ & $<0.01$ \\
$\mathrm{TG}, \mathrm{mmol} / \mathrm{L}$ & $2.16(1.26-4.21)$ & $1.37(0.94-2.95)$ & $<0.01$ \\
FTBAs, $\mathrm{mmol} / \mathrm{L}$ & $3.84 \pm 2.06$ & $3.06 \pm 1.27$ & $<0.01$ \\
HbA1C, \% & $9.69 \pm 2.02$ & $6.51 \pm 0.94$ & $<0.01$ \\
FPG, mmol/L & $9.19 \pm 3.46$ & $6.42 \pm 1.08$ & $<0.01$ \\
FINS, mU/L & $9.44 \pm 5.22$ & $11.02 \pm 4.53$ & 0.128 \\
C-peptide, mU/L & $2.83 \pm 1.03$ & $3.11 \pm 0.84$ & 0.112 \\
HOMA-B & $38.81(20.13-61.98)$ & $79.60(48.47-106.09)$ & $<0.01$ \\
\hline
\end{tabular}

Data presented as means \pm SD or medians (interquartile range)

$P$-value* were calculated by paired sample t test, exe-treatment vs. pre-treatment reabsorption of BAs from the intestinal lumen [23] and therefore decrease total serum BAs [24]. On the other hand, metformin was the first-line treatment agent in T2DM patients, so it was necessary to exclude the influence of metformin.

Our results showed that baseline FTBAs of newly diagnosed T2DM patients did not differ from healthy subjects. This was consistent with Andersen E's study, in which they examined BAs' kinetics in 15 normal glycemic controls and 22 diet-treated T2DM patients and found no difference [25]. These indicated that diabetic disease status had little influence in BAs, at least BAs in fasting state.

After 12-week exenatide treatment for the overweight newly diagnosed T2DM patients group, FTBAs were decreased from $3.84 \pm 2.06$ to $3.06 \pm 1.27 \mu \mathrm{mol} / \mathrm{L}$, with a significance of $P<0.01$. The pharmacokinetics of exenatide twice a day are dose proportional, with maximum serum concentrations after a single subcutaneous dose of 2.5 or $5 \mu \mathrm{g}$ of 56 or $85 \mathrm{pg} / \mathrm{mL}$, respectively, and the area under the concentration-time curve of 159 and $340 \mathrm{pg} \cdot \mathrm{h} / \mathrm{mL}$ [12]. Cui YM et al. reported after subcutaneous injection of $2 \mathrm{mg}$ of exenatide weekly in Chinese T2DM patients, that steady state plasma concentrations $(299 \mathrm{pg} / \mathrm{mL})$ of exenatide were attained within 8 weeks [26]. It was reasonable to assume that the steady state concentrations of exenatide were almost reached after 12-week injection of exenatide. Previous studies showed that serum BAs were reduced in dipeptidyl peptidase-4 (DPP-4) deficient mice compared to wild type mice, which was explained by a reduction in BAs production and enhanced BAs excretion [27]. Moreover, in rat hepatocyte cultures, both GLP-1 peptide and exenatide reduced CYP7A1, the hepatic cytochrome which converted cholesterol to BAs [27]. Our results and previous researches both suggested not a positive effect of exenatide on biliary physiology in overweight T2DM patients. Nevertheless, in the study of Smits MM et al. 2016, they found that liraglutide increased serum levels of deoxycholic acid in the fasting state and postprandial state, and in faeces [14]. The possible reasons might be: 1) the kind of GLP-1 RA drugs was different, exenatide and liraglutide separately; 2) the population was different, Caucasian and Chinese T2DM patients separately; 3) last but not the least, the baseline of T2DM patients was different. Their recruited patients were treated with a dose of metformin and/or sulfonylurea derivatives for at least 3 months. If the effect of metformin on BAs was big enough, the effect of GLP-1 receptor agonists on BAs could be hardly detected, even though the treatment group had the same baseline of metformin intake with the control group. It was hard to tell what was going on exactly before new valid proofs came out.

Through the correlation analysis, we got the result that the decrease of FTBAs was positively correlated with the 
a

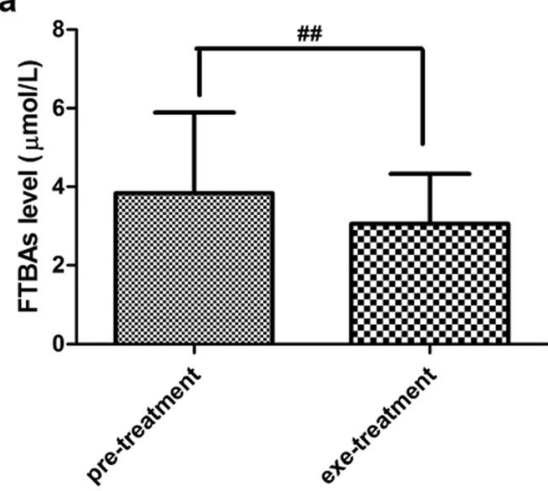

C

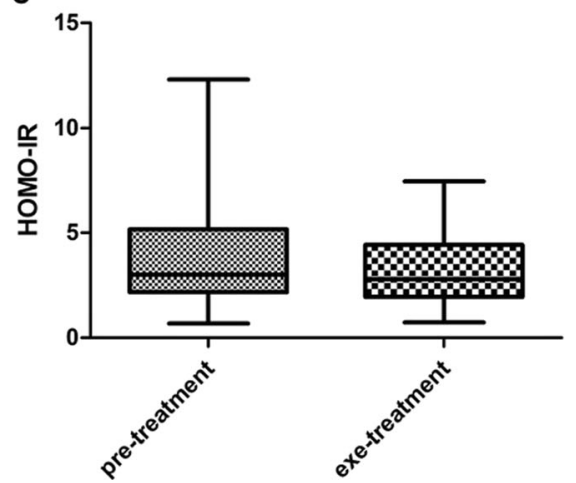

b

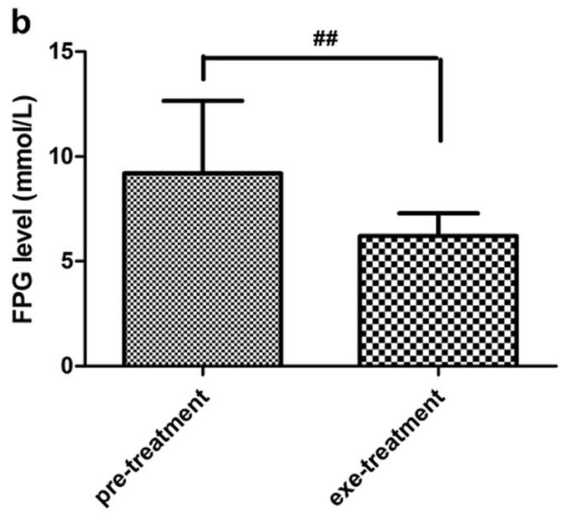

d

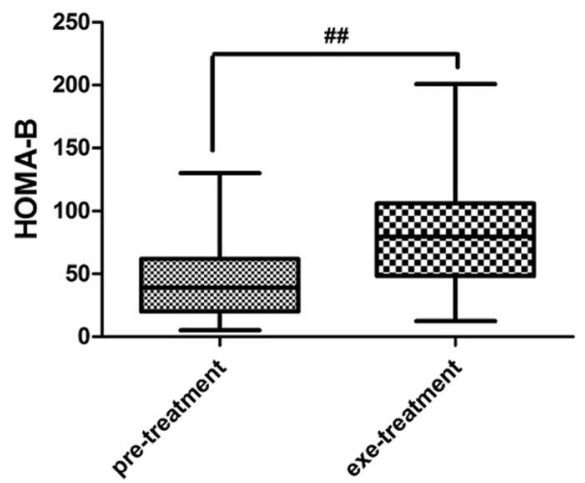

Fig. 1 Changes of glycemic parameters after 12-week exenatide treatment for T2DM patients. a change of FTBAs; $\mathbf{b}$ change of FPG; c change of HOMA-IR; $\mathbf{d}$ change of HOMA-B. ${ }^{\# \#} P<0.01$ vs. pre-treatment

improvement of FPG. Accumulating data suggested that BAs improved metabolism through activation of FXR and TGR5 [28-30]. FXR stimulation reduces hepatic gluconeogenesis and improves insulin sensitivity, while TGR5 activation increases energy expenditure and insulin sensitivity. It is quite possible that BAs may have a role in mediating glycemic control. Based on the facts above, our results suggested that the reduction of FTBAs might not exert a positive role in the glycemic control effect of exenatide.

The limitation of our study included: 1) this study was a pilot exploration on exenatide's biliary effects. More detection about changes of BAs and their metabolites in

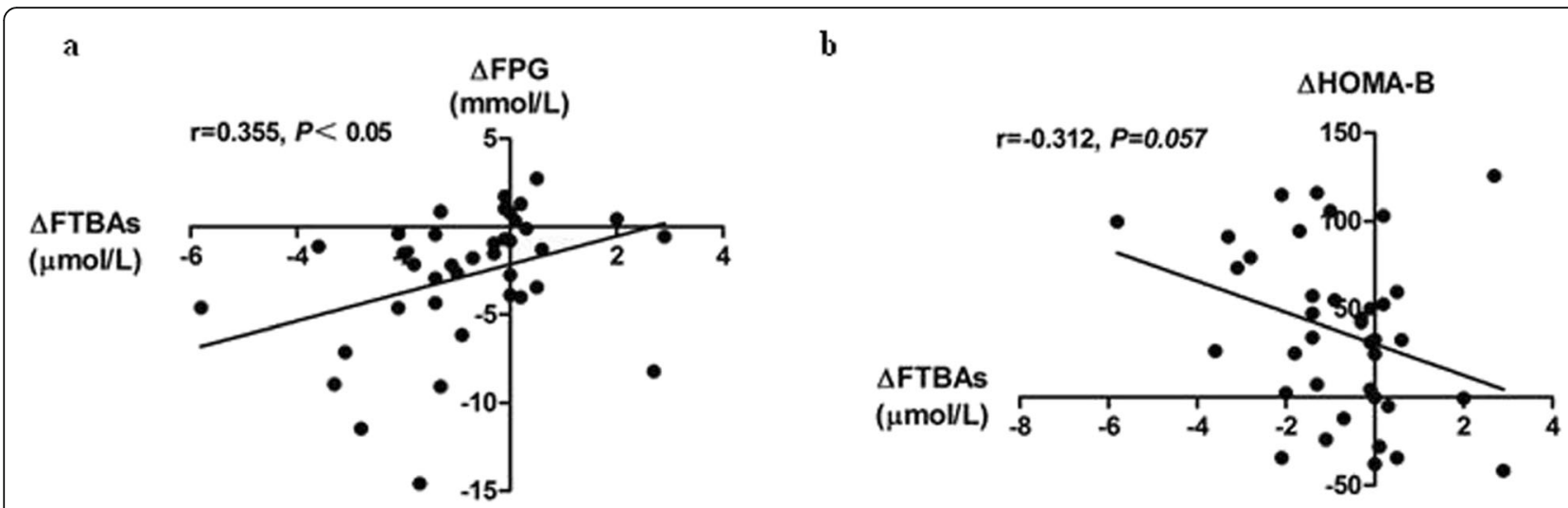

Fig. 2 Correlations between changes of FTBAs ( $\triangle$ FTBAs) and glycemic parameters ( $\triangle F P G, \triangle H O M A-B)$ after 12-week exenatide treatment for T2DM patients. a correlation between $\triangle \mathrm{FTBAs}$ and $\triangle \mathrm{FPG} ; \mathbf{b}$ correlation between $\triangle \mathrm{FTBAs}$ and $\triangle \mathrm{HOMA}-\mathrm{B}$ 
different prandial phases could reveal more; 2) the sample size was small. More statistical significance might appear if the sample size was enlarged.

\section{Conclusions}

In conclusion, our results demonstrated a decreased FTBAs level after exenatide treatment for 12 weeks, without interference of metformin and other glucoselowering drugs. The reduction of FTBAs might not exert a positive role in the glycemic control effect of exenatide.

\section{Abbreviations}

BAs: Bile acids; FTBAs: Plasma total bile acids in fasting state; GLP1: Glucagon-like peptide-1; GLP-1 RA: Glucagon-like peptide-1 receptor agonists; T2DM: Type 2 diabetes mellitus; FPG: Fasting plasma glucose; FINS: Fasting serum insulin; HbA1c: Glycated hemoglobin A1c; HOMAIR: Homoeostasis model assessment for insulin resistance; HOMAB: Homoeostasis model assessment for $\beta$-cell function; BMI: Body mass index; TC: Total cholesterol; LDL-C: Low-density lipoprotein cholesterol; HDLC: High-density lipoprotein cholesterol; TG: Triglyceride; BAS: Bile acids sequestrants; ASBT: Apical sodium-dependent bile acid transporter; TGR5: Takeda G-protein-coupled receptor 5; FXR: Farnesoid X receptor

\section{Acknowledgements}

Thanks for Dr. Jia Liu for discussion about the study design.

\section{Authors' contributions}

$\mathrm{BL}$ designed the study and wrote the manuscript. $\mathrm{YH}$ performed the data analysis. GW and LL were the guarantor of integrity of the entire study and edited the final manuscript. All authors have read and approved the manuscript.

\section{Funding}

This study was supported by National Natural Science Foundation of China (Grants no. 81803500) and Cultivation Project of Beijing Chao-yang Hospital for National Natural Science Foundation of China (Grants no. CYYPY201814). The authors would like to thank the support in study design and collection, analysis, and interpretation of data.

\section{Availability of data and materials}

The datasets used and analyzed during the current study are available from the corresponding author on reasonable request.

\section{Ethics approval and consent to participate}

The study was approved by the ethics committee of Beijing Chao-Yang Hospital and done in accordance with the ethical principles for medical research involving human subjects outlined in the Helsinki Declaration in 1975 (revised in 2013; http://www.wma.net/en/30publications/10policies/b3/index. html). Informed written consent was taken from all participants.

\section{Consent for publication}

Not applicable.

\section{Competing interests}

The authors declare that they have no competing interest.

Received: 23 February 2020 Accepted: 26 May 2020

Published online: 15 June 2020

\section{References}

1. Lund A, Knop FK, Vilsboll T. Glucagon-like peptide-1 receptor agonists for the treatment of type 2 diabetes: differences and similarities. Eur J Int Med. 2014:25:407-14.

2. Smits MM, Tonneijck L, Muskiet MHA, Kramer MH, Cahen DL, van Raalte DH. Gastrointestinal actions of GLP-1 based therapies: glycaemic control beyond the pancreas. Diabetes Obes Metab. 2016;18(2):178-85.
3. Mertens $\mathrm{KL}$, Kalsbeek A, Soeters MR, Eggink HM. Bile acid signaling pathways from the Enterohepatic circulation to the central nervous system. Front Neurosci. 2017. https://doi.org/10.3389/fnins.2017.00617.

4. Hofmann AF, Hagey LR. Bile acids: chemistry, pathochemistry, biology, pathobiology, and therapeutics. Cell Mol Life Sci. 2008;65:2461-83.

5. Yu Q, Jiang Z, Zhang L. Bile acid regulation: a novel therapeutic strategy in non-alcoholic fatty liver disease. Pharmacol Ther. 2018;190:81-90.

6. Adrian TE, Gariballa S, Parekh KA, Thomas SA, Saadi H, Al Kaabi J, et al. Rectal taurocholate increases $\mathrm{L}$ cell and insulin secretion, and decreases blood glucose and food intake in obese type 2 diabetic volunteers. Diabetologia. 2012:55:2343-7.

7. Broeders EP, Nascimento EB, Havekes B, Brans B, Roumans KH, Tailleux A, et al. The bile acid chenodeoxycholic acid increases human brown adipose tissue activity. Cell Metab. 2015;22:418-26.

8. Wu T, Bound MJ, Standfield SD, Gedulin B, Jones KL, Horowitz M, et al. Effects of rectal administration of taurocholic acid on glucagon-like peptide1 and peptide YY secretion in healthy humans. Diabetes Obes Metab. 2013; 15:474-7.

9. Hansen M, Scheltema MJ, Sonne DP, Hansen JS, Sperling M, Rehfeld JF, et al. Effect of chenodeoxycholic acid and the bile acid sequestrant colesevelam on glucagon-like peptide-1 secretion. Diabetes Obes Metab. 2016;18:571-80

10. Brighton CA, Rievaj J, Kuhre RE, Glass LL, Schoonjans K, Holst JJ, et al. Bile acids trigger GLP-1 release predominantly by accessing basolaterally located G protein-coupled bile acid receptors. Endocrinology. 2015;156:3961-70.

11. Knop FK. Bile-induced secretion of glucagon-like peptide-1: pathophysiological implications in type 2 diabetes? Am J Physiol Endocrinol Metab. 2010;299:E10-3.

12. Shapiro $H$, Kolodziejczyk AA, Halstuch D, Elinav E. Bile acids in glucose metabolism in health and disease. J Exp Med. 2018;215(2):383-96. https:// doi.org/10.1084/jem.20171965.

13. Keller J, Trautmann ME, Haber H, Tham LS, Hunt T, Mace $K$, et al. Effect of exenatide on cholecystokinin-induced gallbladder emptying in fasting healthy subjects. Regul Pept. 2012;179:77-83.

14. Smits MM, Tonneijck L, Muskiet MH, Hoekstra T, Kramer MH, Diamant M et al. Biliary effects of liraglutide and sitagliptin, a 12-week randomized placebo-controlled trial in type 2 diabetes patients. Diabetes Obes Metab. 2016:18:1217-25.

15. Hu Y, Liu J, Zhang H, Xu Y, Hong T, Wang G. Exenatide treatment decreases fasting fibroblast growth factor 21 levels in patients with newly diagnosed type 2 diabetes mellitus. Diabetes Metab. 2016;42:358-63.

16. World Health Organization. Definition and classification of diabetes mellitus and its complications. In: Report of a WHO consultation. Part 1: diagnosis and classification of diabetes mellitus. Geneva: WHO; 1999. Department of noncommunicable disease surveillance.

17. Matthews DR, Hosker JP, Rudenski AS, Naylor BA, Treacher DF, Turner RC. Homeostasis model assessment: insulin resistance and beta-cell function from fasting plasma glucose and insulin concentrations in man. Diabetologia. 1985:28:412-9.

18. Simren M, Bajor A, Gillberg PG, Rudling M, Abrahamsson H. Randomised clinical trial: the ileal bile acid transporter inhibitor A3309 vs. placebo in patients with chronic idiopathic constipation-a double-blind study. Aliment Pharmacol Ther. 2011:34:41-50.

19. Rudling M, Camilleri M, Graffner H, Holst JJ, Rikner L. Specific inhibition of bile acid transport alters plasma lipids and GLP-1. BMC Cardiovasc Disord. 2015;15:75.

20. Bays HE, Goldberg RB, Truitt KE, Jones MR. Colesevelam hydrochloride therapy in patients with type 2 diabetes mellitus treated with metformin: glucose and lipid effects. Arch Intern Med. 2008;168:1975-83.

21. Beysen C, Murphy EJ, Deines K, Chan M, Tsang E, Glass A, et al. Effect of bile acid sequestrants on glucose metabolism, hepatic de novo lipogenesis, and cholesterol and bile acid kinetics in type 2 diabetes: a randomised controlled study. Diabetologia. 2012;55:432-42.

22. Karhus ML, Bronden A, Sonne DP, Vilsbøll T, Knop FK. Evidence connecting old, new and neglected glucose-lowering drugs to bile acid-induced GLP-1 secretion: a review. Diabetes Obes Metab. 2017;19:1214-22.

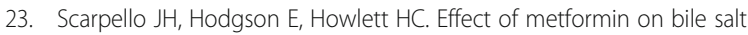
circulation and intestinal motility in type 2 diabetes mellitus. Diabet Med. 1998;15:651-6.

24. Napolitano A, Miller S, Nicholls AW, Baker D, Van Horn S, Thomas E, et al. Novel gut-based pharmacology of metformin in patients with type 2 
diabetes mellitus. PLoS One. 2014. https://doi.org/10.1371/journal.pone. 0100778.

25. Andersen EHP, Hellström K. Cholesterol and bile acid metabolism in middleaged diabetics. Diabete Metab. 1986;12:161-7.

26. Cui YM, Guo XH, Zhang DM, Tham LS, Tang CC, Mace K, et al.

Pharmacokinetics, safety, and tolerability of single- and multiple-dose

Exenatide once weekly in Chinese patients with type 2 diabetes mellitus. J Diabetes. 2013;5(2):127-35.

27. Ben-Shlomo S, Zvibel I, Rabinowich L, Goldiner I, Shlomai A, Santo EM, et al. Dipeptidyl peptidase 4-deficient rats have improved bile secretory function in high fat diet-induced steatosis. Dig Dis Sci. 2013;58:172-8.

28. Schaap FGTM, Jansen PL. Bile acid receptors as targets for drug development. Nat Rev Gastroenterol Hepatol. 2014;11:55-67.

29. Lefebvre P, Cariou B, Lien F, Kuipers F, Staels B. Role of bile acids and bile acid receptors in metabolic regulation. Physiol Rev. 2009;89:147-91.

30. Thomas C, Gioiello A, Noriega L, Strehle A, Oury J, Rizzo G, et al. TGR5mediated bile acid sensing controls glucose homeostasis. Cell Metab. 2009; 10:167-77.

\section{Publisher's Note}

Springer Nature remains neutral with regard to jurisdictional claims in published maps and institutional affiliations.

- fast, convenient online submission

- thorough peer review by experienced researchers in your field

- rapid publication on acceptance

- support for research data, including large and complex data types

- gold Open Access which fosters wider collaboration and increased citations

- maximum visibility for your research: over $100 \mathrm{M}$ website views per year

At $\mathrm{BMC}$, research is always in progress.

Learn more biomedcentral.com/submissions 